\title{
Acute kidney injury in obstetrics: a five-year study in a tertiary centre
}

\author{
Sushma H. Papegowda, Pratima K. Devi*, Ranjit L. Singh, Agalya Muruganadam, \\ Zikpuii L. Tochhawng
}

Department of Obstetrics and Gynecology, Regional Institute of Medical Sciences and Research, Imphal, Manipur, India

Received: 24 September 2019

Revised: 17 November 2019

Accepted: 28 November 2019

*Correspondence:

Dr. Pratima K. Devi,

E-mail: pratimadutta09@gmail.com

Copyright: () the author(s), publisher and licensee Medip Academy. This is an open-access article distributed under the terms of the Creative Commons Attribution Non-Commercial License, which permits unrestricted non-commercial use, distribution, and reproduction in any medium, provided the original work is properly cited.

\begin{abstract}
Background: Pregnancy Related Acute Kidney Injury (PRAKI) is a major cause of maternal and foetal morbidity and mortality in developing countries. The incidence has declined due to improvements in reproductive health but it is still associated with significant perinatal mortality and maternal morbidity. It may be due to decrease in renal perfusion or ischemic tubular necrosis from a variety of conditions encountered during pregnancy. Our study aims at determining the predisposing factors and causes of AKI during pregnancy and its impact on maternal and foetal outcome.

Methods: A retrospective cohort study over a period of 5 years was conducted on pregnant women with AKI as per inclusion and exclusion criteria. The detailed history, events, mode of delivery, cause leading to AKI, management, hospital stay, maternal and foetal outcome were studied in detail and evaluated. These patients were classified according to RIFLE criteria and were followed up for hospital stay and residual morbidities.

Results: The incidence of PRAKI in the study was $0.07 \%$ (36 out of 50,735 deliveries) and among obstetric ICU patients, it was $6.8 \%$. Most of the majority of the cases were unbooked (66.7\%) and multipara (61.1\%). Maternal morbidity was seen in $66.7 \%$ and mortality was $27.8 \%$. Poor foetal outcome was seen in $44.4 \%$.

Conclusions: Haemorrhage is the most common cause of PRAKI, followed by toxaemia of pregnancy and sepsis. Early detection and meticulous management of haemorrhage, hypertension and sepsis reduce the incidence of PRAKI and associated maternal mortality.
\end{abstract}

Keywords: Foetal outcome, Maternal outcome, Pregnancy related acute kidney injury, RIFLE criteria

\section{INTRODUCTION}

In pregnancy, acute renal injury usually occurs in women with previously healthy kidneys, but it can complicate the course of patients with pre-existing renal disease. ${ }^{1}$ The incidence has declined due to improvements in reproductive health and perinatal care but it is still associated with significant perinatal mortality and maternal morbidity. ${ }^{2}$

\section{AKI is defined as any of the following}

Increase in $\mathrm{SCr}$. by $\geq 0.3 \mathrm{mg} / \mathrm{dl}(\geq 26.5 \mu \mathrm{mol} / \mathrm{L})$ within 48 hours; or

Increase in $\mathrm{SCr}$ to $\geq 1.5$ times baseline, which is known or presumed to have occurred within prior 7 days; or

Urine volume $<0.5 \mathrm{ml} / \mathrm{kg} / \mathrm{h}$ for 6 hours. $^{3}$ 
Acute kidney injury (AKI) is a heterogeneous syndrome defined by a rapid decline in the glomerular filtration rate (GFR). ${ }^{4}$ PRAKI (Pregnancy poses a challenge of different level to clinicians taking care of these patients). ${ }^{5}$ It is a major cause of maternal and foetal morbidity and mortality in developing countries. ${ }^{6}$ The incidence and the mortality associated with PRAKI have decreased in developed countries from $40 \%$ to $20 \%$ in 1960 to <10\% in recent series mostly due to meticulous antenatal management. ${ }^{7}$ Female gender is as such increases the susceptibilities for non-specific AKI. ${ }^{3}$ PRAKI may be due to a decrease in renal perfusion or ischemic tubular necrosis from a variety of conditions. ${ }^{7}$ These include hyperemesis gravidarum, postpartum haemorrhage, hypertensive disorders, thrombotic microangiopathies, acute fatty liver of pregnancy, septic abortion, sepsis, acute fatty liver of pregnancy and complicated urinary tract infections. ${ }^{8}$ Recently reported incidence of postpartum AKI (PP-AKI) is $10.55 \%$ sepsis and haemorrhage being the commonest aetiologies. ${ }^{9}$

\section{Incidence}

Incidence of pregnancy related AKI used to be $24-40 \%$ of all AKI in 60's which decreased to $2-3 \%$ in 80 's. ${ }^{10}$ The incidence of PRAKI is a more common problem in the developing nations. ${ }^{11}$ The incidence of obstetric AKI has further declined over last 4 decades. ${ }^{12}$ The lesser incidence of this problem is due to the improvement in antenatal care and the reduction of septic abortion due to its legalisation. ${ }^{1,13,14}$ Socioeconomic factors contributing to PRAKI in the developing countries are mainly due to poverty, poor obstetrics care, lack of proper healthcare facilities and awareness of the condition, delayed referral process, multiparity, and the increasing population number. ${ }^{15}$ Some studies summarized that the incidence of PRAKI was $1.0 \%$ to $2.8 \%$ in developed nations versus $4 \%-26 \%$ in developing countries. ${ }^{1,2,12-15}$ A study from India revealed a decrease in PRAKI incidence from $22 \%$ between 1965 and 1974 to $9 \%$ between 1981 and 1986,which was the result of better obstetrical care and increased availability of medical facilities. ${ }^{16}$

\section{Definitions and criteria}

RIFLE: Increase in SCr X 1.5 or GFR decrease $>25 \% .{ }^{17}$

$A K I N$ : Increase in $\mathrm{SCr}$ by $\geq 0.3 \mathrm{mg} / \mathrm{dl}$ or increase $\geq 150 \%$ to $200 \%$ ( 1.5 to 2 -fold) from baseline within 48 hours. ${ }^{17}$

Table 1: Classification and staging system for AKI. ${ }^{18}$

\begin{tabular}{|lll|}
\hline System & Serum creatinine criteria & Urine output \\
\hline RIFLE class & \\
\hline Risk & SCr increase to 1.5 -fold or GFR decrease $>25 \%$ from baseline & $<0.5 \mathrm{ml} / \mathrm{kg} / \mathrm{h}$ for 6 hours \\
\hline Injury & SCr increase to 2-fold or GFR decrease $>50 \%$ from baseline & $<0.5 \mathrm{ml} / \mathrm{kg} / \mathrm{h}$ for 12 hours \\
\hline Failure & $\begin{array}{l}\text { SCr increase to 3-fold or GFR decrease }>75 \% \text { from baseline or } \\
\text { Scr } \geq 354 \mu \mathrm{mol} / 1(\geq 4 \mathrm{mg} / \mathrm{dl}) \text { with an acute increase of at least } 44 \\
\mu \mathrm{mol} / 1(0.5 \mathrm{mg} / \mathrm{dl})\end{array}$ & Anuria for 12 hours \\
\hline AKIN stage & $\begin{array}{l}\text { SCr increase } \geq 26.5 \mu \mathrm{mol} / \mathrm{l}(>0.3 \mathrm{mg} / \mathrm{dl}) \text { or increase to } 1.5-2 \text { from } \\
\text { baseline }\end{array}$ & $<0.5 \mathrm{ml} / \mathrm{kg} / \mathrm{hr}$ for 6 hours \\
\hline 1 & $\begin{array}{l}\text { SCr increase }>2.0 \text { to } 3 \text { fold from baseline } \\
\text { SCr increase }>3 \text {-fold from baseline or } \mathrm{SCr} \geq 354 \mu \mathrm{mol} / 1(\geq 4 \\
\mathrm{mg} / \mathrm{dl}) \text { with an acute increase of at least } 44 \mu \mathrm{mol} / 1(0.5 \mathrm{mg} / \mathrm{dl}) \text { or } \\
\text { need for RRT }\end{array}$ & $\begin{array}{l}<0.3 \mathrm{ml} / \mathrm{kg} / \mathrm{hr} \text { for } 24 \text { hours or anuria } \\
\text { for } 12 \mathrm{hours} \text { or need for RRT }\end{array}$ \\
\hline 2 & & \\
\hline
\end{tabular}

A RIFLE criterion stratifies AKI into five stages (Table 1). There are differences between the two systems. Time constraint is used in AKIN criteria whereas GFR decreases are used in RIFLE criteria.

KDIGO: Increase in $\mathrm{SCr}$ by $\geq 0.3 \mathrm{mg} / \mathrm{dl}$ within 48 hours or to $\geq 1.5$ times the baseline, known or presumed to have occurred within prior 7 days.

Aetiology $^{19}$

AKI during early pregnancy
- Acute or massive blood loss

a. Abortion

b. Ruptured ectopic pregnancy

c. Hydatidiform mole

- Severe dehydration

a. Acute pyrlonephritis

b. Hyperemesis gravidarum

- Acute tubular necrosis (ATN)

a. Septic abortion.

\section{AKI during late pregnancy}

- Thrombotic microangiopathy 
a. TTP - HUS

b. Severe preeclampsia, HELLP syndrome

- Renal cortical necrosis due to

a. APH: abruption placenta, placenta previa

b. Prolonged IUD

c. Amniotic fluid embolism

- Intrinsic renal disease/ autoimmune disease

- Acute pyelonephritis

- ATN
a. Septicaemia
b. Hypotension

- Acute fatty liver of pregnancy

- Obstructive causes.

\section{AKI during postpartum period}

- Massive blood loss due to PPH

- Thrombotic microangiopathy a. HELLP syndrome, preeclampsia

- ATN

$$
\text { a. Puerperal sepsis }
$$

- $\quad$ Postoperative AKI
a. Blood loss
b. Intraoperative hypotension.

\section{Pathogenesis}

The conditions that precipitate the deterioration in function may be pre-renal, renal parenchymal or post renal in origin. ${ }^{18}$

\section{Pre-renal failure}

A mild form of acute renal failure caused by moderate degrees of renal ischemia. It is reversible if renal perfusion is restored. Pre-renal azotemia is the most common form of AKI.

\section{Acute tubular necrosis}

This follows more prolonged ischemia. It is also reversible. Damage is limited to metabolically active tubular cells.

\section{Acute cortical necrosis}

This follows severe renal ischemia that causes disintegration of both glomeruli and tubules in the renal cortex. Although the process is irreversible, it is the incomplete or patchy variety that occurs more often in pregnancy.

\section{Three subsequent phases of AKI}

\section{Oliguria}

Urine output of $<400 \mathrm{ml}$ in 24 hours lasting days to weeks.

\section{Polyuria}

Markedly increased urine output lasting days to weeks. During this phase plasma urea and creatinine levels usually continue to rise. As large volumes of urine may be passed, careful attention must be given to fluid and electrolyte replacement. During this phase the renal tubular cells are recovering but not yet able to concentrate urine.

\section{Recovery}

Urine output reverts towards normal with complete or variable return of renal function.

The objective of this study was to determine the risk factors and to analyse the clinical spectrum and outcome of acute kidney injury (AKI) in obstetric patients.

\section{METHODS}

This was a retrospective cohort study conducted in patient department of obstetrics and gynaecology, Regional Institute of Medical Sciences, Imphal, Manipur, India.

This was a five-year study starting from March 2014 to February 2019 included 36 pregnant women who developed kidney injury due to pregnancy related causes.

\section{Inclusion criteria}

- Pregnant women admitted for safe confinement who later developed AKI

- Pregnant women who were admitted for complications which later progressed to AKI

- Patient giving consent for participating in the study.

\section{Exclusion criteria}

- Pregnant women with prior kidney failure

- Chronic kidney disease patients

- Pregnant women with medical disorder as a direct cause of AKI.

Sample size calculated using the formula $(n)=z^{2} \times p \times q / L^{2}$

\section{Sampling method}

Convenience sampling was done to include all pregnant patients who developed acute kidney injury during the course of pregnancy

\section{Study variables}

\section{Independent variables}

Age, religion, residence, education, occupation, parity, number of ANC check-ups, number of living issues, birth 
spacing, booking status, history of abortion, age of menarche, past history, level of anaemia, renal function test, mode of delivery.

\section{Dependent variables}

Risk factors of AKI in pregnant women, foetal and maternal outcome.

\section{Study tools}

The case sheets of all the patients who developed acute kidney injury were analyzed in detail for the history, examination findings and investigations were studied.

\section{Procedure}

A retrospective cohort study over a period of 5 years was conducted on pregnant women admitted in Regional Institute of Medical Sciences and who met the criteria of AKI. The detailed history, events, mode of delivery, cause leading to AKI, management, hospital stay, maternal and foetal outcome were studied in detail and evaluated. These patients were classified according to RIFLE criteria and were followed up for hospital stay and residual morbidity.

\section{Statistical analysis}

Data was checked for consistency and completeness, and was entered and analyzed using SPSS version 21.0 IBM for Windows. Descriptive statistics such as frequency, percentage, mean and standard deviation were used. Chisquare/ Fisher Exact test has been used to find the significance of study parameters on categorical scale between two or more groups.

\section{RESULTS}

During the 5 years study, 50735 deliveries were conducted in RIMS among which 530 critical patients were admitted in Obstetrics ICU. Among those 536 critical patients AKI complicated the course of 36 patients representing an incidence of $6.8 \%$. Among 36 patients, 10 patients had mortality, 26 patients recovered after prolonged hospital stay, 9 patients had to undergo dialysis at least once. Majority of the cases belonged to age group of more than 20 years $(63.9 \%)$ as shown in Table 2.

Table 2: Distribution of cases according to age $(\mathbf{N}=36)$.

\begin{tabular}{|lll|}
\hline Age & No. of patients & $\%$ \\
\hline$\leq 20$ years & 13 & $36.1 \%$ \\
\hline$>20$ years & 23 & $63.9 \%$ \\
\hline Total & $\mathbf{3 6}$ & $\mathbf{1 0 0 . 0}$ \\
\hline
\end{tabular}

Most of these cases belonged to low socioeconomic status and rural area. Among these $38.9 \%$ cases were primigravida (Table 3).

Table 3: Distribution of cases according to parity $(\mathrm{N}=36)$.

\begin{tabular}{|lll|}
\hline Parity & No. of patients & $\%$ \\
\hline Primi & 14 & 38.9 \\
\hline Multi & 22 & 61.1 \\
\hline Total & $\mathbf{3 6}$ & $\mathbf{1 0 0 . 0}$ \\
\hline
\end{tabular}

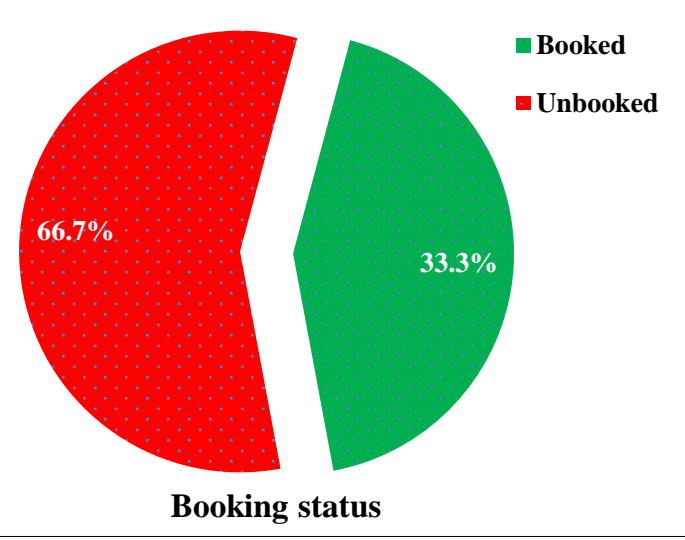

Figure 1: Distribution of cases according to booking status $(\mathbf{N}=36)$.

Table 4: Distribution of cases according to residence $(\mathrm{N}=36)$.

\begin{tabular}{|lll|}
\hline Residence & No. of patients & $\%$ \\
\hline Urban & 14 & 38.9 \\
\hline Rural & 22 & 61.1 \\
\hline Total & $\mathbf{3 6}$ & $\mathbf{1 0 0 . 0}$ \\
\hline
\end{tabular}

Primigravida constitutes around $38.9 \%$ and multipara constitutes majority (61.1\%). Among primigravida, toxaemia of pregnancy was found to be the leading cause whereas haemorrhage was the leading cause in multiparity women.

Table 5: Distribution of cases according to riskRIFLE criteria $(\mathbf{N}=36)$.

\begin{tabular}{|lll|}
\hline Risk & No. of patients & $\%$ \\
\hline Present & 30 & 83.3 \\
\hline Absent & 6 & 16.7 \\
\hline Total & $\mathbf{3 6}$ & $\mathbf{1 0 0 . 0}$ \\
\hline
\end{tabular}

Majority (66.7\%) of cases were unbooked cases (Table 4). Inadequate antenatal visit is one of the main predisposing factors leading to complications during labour and hence causing poor pregnancy outcome (Figure 1). More than half $(61.1 \%)$ of the cases belonged to rural area (Table 4). Poor access to health care facilities, poor management of complications and late 
referral from the primary health centres were some of the reasons of having a poor pregnancy outcome among women from rural area.

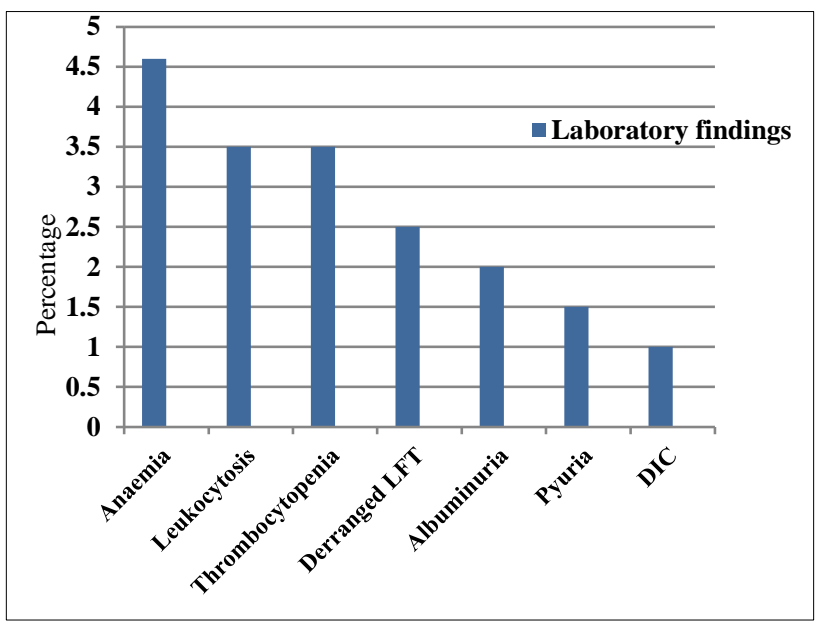

Figure 2: Percentage of laboratory findings in AKI patients.

Risk was observed in majority $(83.3 \%)$ of the cases (Table 5). Acute kidney injury was more commonly seen among those who had prior risk factors like hypertensive disorders, infection, anaemia and autoimmune disorders (Figure 2).

Table 6: Distribution of cases according to RIFLEinjury $(\mathrm{N}=36)$.

\begin{tabular}{|lll|}
\hline Injury & No. of patients & $\%$ \\
\hline Present & 36 & 100 \\
\hline Absent & 0 & 0 \\
\hline Total & $\mathbf{3 6}$ & $\mathbf{1 0 0 . 0}$ \\
\hline
\end{tabular}

Table 7: Distribution of case RIFLE - failure ( $N=36)$.

\begin{tabular}{|lll|}
\hline Failure & No. of patients & $\%$ \\
\hline Yes & 24 & $66.7 \%$ \\
\hline No & 12 & $33.3 \%$ \\
\hline Total & $\mathbf{3 6}$ & $\mathbf{1 0 0 . 0}$ \\
\hline
\end{tabular}

Table 8: Distribution of cases according to RIFLE loss $(\mathrm{N}=36)$.

\begin{tabular}{|lll|}
\hline Loss & No. of patients & $\%$ \\
\hline Yes & 24 & $66.7 \%$ \\
\hline No & 12 & $33.3 \%$ \\
\hline Total & $\mathbf{3 6}$ & $\mathbf{1 0 0 . 0}$ \\
\hline
\end{tabular}

It was observed that all the patients (100\%) had injury (Table 6). Injury was either due to decreased perfusion or due to tubular injury. These injuries were due to haemorrhage $(57 \%)$, sepsis $(13 \%)$, toxaemia of pregnancy $(12 \%)$, anaemia $(10 \%)$, pyelonephritis $(5 \%)$ and autoimmune disorders $(3 \%)$ as shown in Figure 2.
Failure was observed in majority $(66 \%)$ of patients with AKI (Table 7). 12 Patients among those diagnosed with failure stage of RIFLE criteria underwent renal dialysis.

Table 9: Distribution of cases according to RIFLE end stage renal disease $(\mathrm{N}=36)$.

\begin{tabular}{|lll|}
\hline Loss & No. of patients & $\%$ \\
\hline Yes & 12 & $33.3 \%$ \\
\hline No & 24 & $66.7 \%$ \\
\hline Total & $\mathbf{3 6}$ & $\mathbf{1 0 0 . 0}$ \\
\hline
\end{tabular}

It was observed renal tubular loss was seen in majority (66.7\% as shown in Table 8) and majority of those patients with significant tubular loss progressed to End stage renal disease (Table 9).

Table 10: Distribution of cases according to maternal mortality $(\mathrm{N}=36)$.

\begin{tabular}{|lll|}
\hline Mortality & No. of patients & $\%$ \\
\hline Yes & 10 & $27.8 \%$ \\
\hline No & 26 & $72.2 \%$ \\
\hline Total & $\mathbf{3 6}$ & $\mathbf{1 0 0 . 0}$ \\
\hline
\end{tabular}

End stage renal disease was observed in nearly quarter of cases $(33.3 \%)$. Majority of the patients with end stage renal disease had maternal mortality $(27.8 \%)$ as shown in Table 10

It was observed that AKI had a mortality rate of $27.8 \%$ and majority $(72.2 \%)$ of the patients were recovered. Majority of those patients with failure and ESRD had worst prognosis.

\section{Table 11: Distribution of cases according to foetal} outcome $(\mathbf{N}=36)$.

\begin{tabular}{|lll|}
\hline $\begin{array}{l}\text { Abortion/IUD/ neonatal } \\
\text { mortality }\end{array}$ & $\begin{array}{l}\text { No. of } \\
\text { patients }\end{array}$ & $\%$ \\
\hline Yes & 16 & $44.4 \%$ \\
\hline No & 20 & 55.6 \\
\hline Total & $\mathbf{3 6}$ & $\mathbf{1 0 0 . 0}$ \\
\hline
\end{tabular}

Poor foetal outcome was observed in nearly half of the cases (44.4\% as shown in Table 11). Poor foetal outcome was seen in terms of abortion, IUD, Preterm birth and Neonatal mortality.

Anaemia was the most common laboratory finding which reflects the laboratory picture of haemorrhage and hence haemorrhage was the leading cause of AKI followed by leucocytosis and thrombocytopenia (Figure 2). Leucocytosis was seen in patients with infection. Thrombocytosis was a laboratory picture of HELLP syndrome and DIC.

Our study shows that the haemorrhage is the most common cause of AKI in obstetrics followed by toxemia 
of pregnancy and septicaemia (Figure 3). Cases with combination of toxaemia of pregnancy and haemorrhage or sepsis and haemorrhage had the worst prognosis.

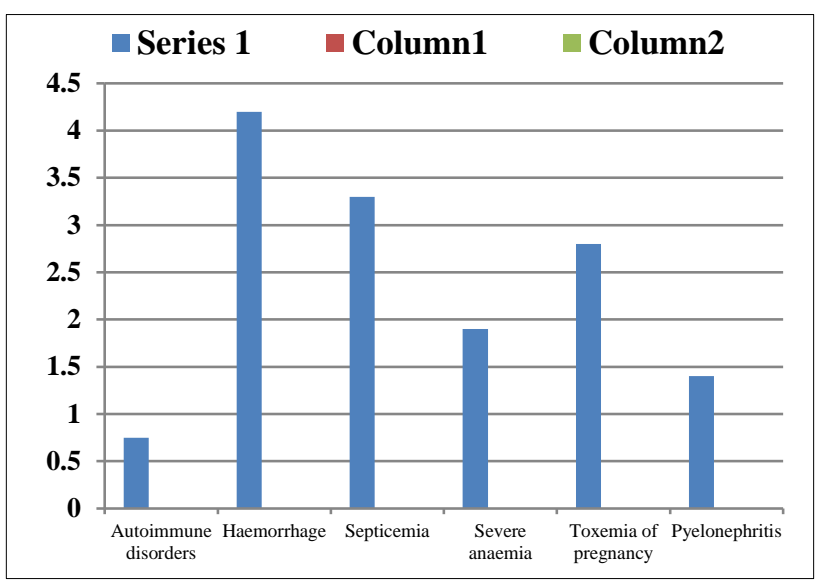

Figure 3: Distribution of cases according to the causes of AKI.

\section{DISCUSSION}

Study reports AKI occurred in 36 patients out of 530 critical patients admitted in obstetrical HDU reflecting the incidence of PRAKI in our hospital as $6.8 \%$. Out of those 36 patients $25 \%$ required dialysis. Study conducted by Jonard $\mathrm{M}$ et al, shows the similar percentage of patients who needed dialysis; however, incidence seems lesser in our study. ${ }^{4}$ Several demographic factors and meticulous management might have influenced the occurrence of obstetric AKI. Since us was a referral hospital, most of the cases were referred in last stage and hence were unbooked cases, most of patients had received NSAIDS in PHC, most of the abortions were due to abortificients taken over the counter, septic abortions were due to late report and illegal abortions. Most of the unbooked cases had inadequate antenatal visits, one reason being people residing in hilly areas had difficulties for regular antenatal visits and some had home deliveries. Study shows that $67.7 \%$ of these patients were unbooked and had irregular antenatal consultation. Munib S et al, reported $84 \%$ who did not receive antenatal care and Goplani $\mathrm{KR}$ et al, reported $15.71 \%$ home deliveries. ${ }^{5,6}$

In this study $61.1 \%$ were from rural areas. Dambal A et al, reported $73.3 \%$ were from rural and Goplani KR et al, also reported $70 \%$ were from rural. ${ }^{7}$ Patients in rural areas would have delayed early access during the emergency even though toxaemia was more common in urban residency patients.

Multipara were $61.1 \%$ and this result was consistent with the study conducted by Dambal et al that showed $66.6 \%$ were multipara.

In $66.7 \%$ of obstetric AKI, stage of failure was found and $33.3 \%$ of the cases progressed to Loss and End stage renal disease of RIFLE criteria $83.3 \%$ of those with loss and end stage renal disease had mortality. Those patients who reported in early stage, progression to failure, loss and end stage renal disease was halted due to coverage of broad-spectrum antibiotic, fluid restriction and dialysis.

The haemorrhage is the most common cause of AKI in obstetrics followed by Toxemia of pregnancy and septicaemia. Haemorrhage associated with toxaemia of pregnancy or septicaemia had the worst prognosis and poor feto-maternal outcome.

\section{CONCLUSION}

Postpartum haemorrhage is the leading cause of AKI reflecting peripartum AKI accounts for maximum of Pregnancy related AKI. Toxaemia of pregnancy and septicaemia are the other main leading causes of PRAKI. Hence a good antenatal care, better access to health facilities, better intrapartum care, meticulous management of PPH, good coverage of antibiotic can reduce the incidence of obstetric AKI.

Funding: No funding sources

Conflict of interest: None declared

Ethical approval: The study was approved by the Institutional Ethics Committee

\section{REFERENCES}

1. Mahesh E, Puri S, Varma V, Madhyastha PR, Bande S, Gurudev KC. Pregnancy related acute kidney injury: An analysis of 165 cases. Indian J Nephrol 2017;27(2):113-7.

2. Arora N, Mahajan K, Jana N, Taraphder A. Pregnancy related acute renal failure in eastern India. Int J Gynecol Obstet. 2010;111(3):213-6.

3. Kidney Disease Improving Global Outcomes. KDIGO Guidelines on AKI, 2014. Available at: https://kdigo.org/wp-content/uploads/2017/04/KD IGO-AKI-Guideline_Cass-2014.pdf. Accessed on $24^{\text {th }}$ February 2019.

4. Eshwarappa M, Madhyastha PR, Puri S, Varma V, Bhandari A, Gurudev C. Postpartum acute kidney injury: a review of 99 cases. Renal Failure 2016;38(6):889-93.

5. Munib S, Khan SJ. Outcome of pregnancy related acute renal failure. RMJ. 2008;33(2):189-92.

6. Goplani KR, Chinta RK, Vishnubhotla SK. Pregnancy related acute renal failure. J Obstet Gynecol India. 2006;56(4):308-10.

7. Dambal A, Lakshmi KS, Gorikhan G, Umadi MM, Kalsad ST, Madhavaranga MP, et al. Obstetric acute kidney injury; a three-year experience at a medical college hospital in North Karnataka, India. J Clin Diagn Res. 2015;9(3):1-14.

8. Turney JH, Ellis CM, Parsons FM. Obstetric acute renal failure 1956-1987. Br J Obstet Gynaecol. 1989;96(6):679-87. 
9. Mir MM, Nair MS, Chaudary AM, Azad H, Reshi AR, Banday KA et al. Postpartum acute kidney injury: experience of a tertiary care centre. Indian $\mathbf{J}$ Nehrol. 2017;27:181-4.

10. Siribamrungwong M, Chinudomwong P. Relation between acute kidney injury and pregnancy-related factors. J Acute Dis. 2016;5(1):22-8.

11. Cunningham FG, Williams JW. Williams obstetrics $\left(24^{\text {th }}\right.$ ed.). Renal and Urinary Tract Disorders. Norwalk, McGraw-Hill; 2014:1063-1064.

12. Aggarwal RS, Mishra VV, Jasani Af, Gumber M. Acute renal failure in pregnancy. Saudi J Kidney Dis Transpl. 2014;25(2):450-5.

13. Baskett TF, O'Conell CM. Maternal critical care in obstetrics. J Obstet Gynaecol Can. 2009;31:218-21.

14. Stewart GK, Goldstein PJ. Theurapeutic abortion in California. Effects of septic abortion and maternal mortality. Obstet Gynaecol. 1971;37:510-4.

15. Ford JB, Roberts CL, Simpson JM, Vaughan J, Cameron CA. Increased postpartum hemorrhage rates in Australia. Int $\mathbf{J}$ Gynecol Obstet. 2007;98:237-43.
16. Prakash J. The kidney in pregnancy: a journey of three decades. Indian J Nehrol. 2012;22:159-67.

17. Lopes JA, Jorge S. The RIFLE and AKIN classifications for acute kidney injury: a critical and comprehensive review. Clin Kid J. 2013;6:8-14.

18. Khanal N, Ahmed E, Akhtar F. Epidemiology, causes and outcome of obstetric acute kidney injury. Novel insights on chronic kidney disease, acute kidney injury and polycystic kidney disease. Rijeka, InTech. 2012:67-81.

19. Lindheimer MD, Grunfeld JP, Davison JM. Renal Disorders. In: Barron WM, Lindheimer MD, Davison JM (eds). Medical Disorders during Pregnancy (2 ${ }^{\text {nd }}$ ed.) Mosby: St. Louis; 1995:37-62.

Cite this article as: Papegowda SH, Devi PK, Singh RL, Muruganadam A, Tochhawng ZL. Acute kidney injury in obstetrics: a five-year study in a tertiary centre. Int J Reprod Contracept Obstet Gynecol 2020;9:113-9. 